\title{
Comparison of the efficacy of a forced-air warming system and circulating-water mattress on core temperature and post-anesthesia shivering in elderly patients undergoing total knee arthroplasty under spinal anesthesia
}

\author{
Hye Young Kim ${ }^{1}$, Kyu Chang Lee ${ }^{1}$, Myeong Jong Lee ${ }^{1}$, Mi-Na Kim ${ }^{1}$, Ji-Sub Kim ${ }^{1}$, Won Sang Lee ${ }^{1}$, and \\ Jung Hwa Lee ${ }^{2}$ \\ Departments of ${ }^{1}$ Anesthesiology and Pain Medicine, ${ }^{2}$ Pediatrics, Chungju Hospital, Konkuk University Medical School, Chungju, Korea
}

Background: In the present study, we compared changes in body temperature and the occurrence of shivering in elderly patients undergoing total knee arthroplasty under spinal anesthesia during warming with either a forced-air warming system or a circulating-water mattress.

Methods: Forty-six patients were randomly assigned to either the forced-air warming system $(\mathrm{N}=23)$ or circulatingwater mattress $(\mathrm{N}=23)$ group. Core temperature was recorded using measurements at the tympanic membrane and rectum. In addition, the incidence and intensity of post-anesthesia shivering and verbal analogue score for thermal comfort were simultaneously assessed.

Results: Core temperature outcomes did not differ between the groups. The incidence $(13.0$ vs $43.5 \%, \mathrm{P}<0.05)$ and intensity $(20 / 2 / 1 / 0 / 0$ vs $13 / 5 / 3 / 2 / 0, \mathrm{P}<0.05)$ of post-anesthesia shivering was significantly lower in the forced-air system group than in the circulating-water mattress group.

Conclusions: The circulating-water mattress was as effective as the forced-air warming system for maintaining body temperature. However, the forced-air warming system was superior to the circulating-water mattress in reducing the incidence of post-anesthesia shivering. (Korean J Anesthesiol 2014; 66: 352-357)

Key Words: Shivering, Spinal anesthesia, Temperature.

\footnotetext{
Received: August 26, 2013. Revised: 1st, October 1, 2013; 2nd, November 2, 2013; 3rd, November 22, 2013; 4th, November 28, 2013; 5th, December 2, 2013. Accepted: December 4, 2013.

Corresponding author: Hye Young Kim, M.D., Department of Anesthesiology and Pain Medicine, Chungju Hospital, Konkuk University Medical School, 620-5, Kyohyun2-dong, Chungju 380-704, Korea. Tel: 82-43-840-8290, Fax: 82-43-843-9251, E-mail: hae1127@kku.ac.kr

(c) This is an open-access article distributed under the terms of the Creative Commons Attribution Non-Commercial License (http:// creativecommons.org/licenses/by-nc/3.0/), which permits unrestricted non-commercial use, distribution, and reproduction in any medium, provided the original work is properly cited.
} 


\section{Introduction}

Spinal anesthesia is known to significantly impair thermoregulation by inhibiting vasomotor and shivering responses and by redistributing heat from the core of the body to peripheral tissues [1]. Core hypothermia $\left(<36^{\circ} \mathrm{C}\right)$ is common in patients who have undergone anesthesia, and may be associated with surgical wound infection, decreased immunity, coagulopathy, an increased incidence of cardiac morbidity, postoperative shivering, prolongation of hospital stay and prolonged effects of anesthetic drugs $[2,3]$. Moreover, post-anesthesia shivering may occasionally be associated with deleterious risks in patients with compromised heart function, since it increases cardiac output and oxygen consumption. Frank et al. [4] reported that one of the risk factors for developing hypothermia after spinal anesthesia is advanced age. Thermoregulation via shivering and vasoconstriction was not as effective in elderly patients who received spinal anesthesia as in younger patients under similar conditions [5]. Several pharmacological and mechanical methods have been used in an attempt to maintain normothermia in the operating room and to prevent post-anesthesia shivering. Insulation of the skin to reduce heat loss, heating of the operating room, and humidification and warming of inhaled gas have all been used to prevent hypothermia during anesthesia [6]. The heating pad was as effective as the forced-air warming system in preventing intraoperative hypothermia under spinal anesthesia $[7,8]$. However, to our knowledge there have been no reports directly comparing the use of a forced-air warming system with that of a circulation-water mattress in elderly patients.

We evaluated the efficacy of a forced-air warming system versus a circulating-water mattress in preventing a decrease in core temperature and post-anesthesia shivering in elderly patients during spinal anesthesia for total knee arthroplasty.

\section{Materials and Methods}

After obtaining institutional approval and written informed consent from all patients, 46 patients with American Society of Anesthesiologists physical status of I-III, aged 65 years and above, who were scheduled for elective total knee arthroplasty under spinal anesthesia, were included in this prospective, randomized study. Exclusion criteria included history of head injury, thyroid disease, severe cardiovascular and respiratory disease, a core temperature of $\geq 37.5^{\circ} \mathrm{C}$, any contraindications to regional anesthesia.

Patients were randomly allocated to one of two groups based upon a warming device; the forced-air warming system (Bair Hugger warming unit-Model 505, Arizant Healthcare, Eden Prairie, USA) or the circulating-water mattress (Blanketrol ${ }^{\circledR} \mathrm{II}$, Cincinnati Sub-Zero, Cincinnati, USA). During the periopera- tive period, the ambient temperature was maintained at $21-23^{\circ} \mathrm{C}$ in the operating room and at $24-26^{\circ} \mathrm{C}$ in the recovery room. All intravenous fluids were warmed to $37^{\circ} \mathrm{C}$ with an infusion warmer.

The patients' chest, abdomen, and arms were covered with two cotton surgical drapes, and the patients were not actively warmed before spinal anesthesia. No preoperative medication was used. Standard monitoring included noninvasive blood pressure and heart rate, electrocardiography, and pulse oximetry. An infrared tympanic thermometer (Instant Thermometer HM3, Braun, San Diego, USA) was used to measure the temperature of patients in both groups. First tympanic temperature was measured immediately after transfer to the operating table. Thereafter, $8 \mathrm{ml} / \mathrm{kg}$ of warmed Ringer's lactate solution was infused intravenously over $15 \mathrm{~min}$. Spinal anesthesia was performed at the L3-4 or L4-5 interspaces in the lateral position by using a 23-gauge Quincke spinal needle to inject 6.5-8.0 mg of $0.5 \%$ hyperbaric bupivacaine. The level of sensory block was assessed via pinprick and cold sensation tests.

After performing spinal anesthesia, a rectal thermistor temperature probe was inserted $10-12 \mathrm{~cm}$ above the anal sphincter and the temperature was monitored continuously until the end of anesthesia. First rectal temperature was recorded every 5 min after initial equilibration. In the forced-air group, the blanket was applied after the induction of anesthesia. In the circulatingwater group, the circulating-water mattress was placed on the operating table and warming started 10 min before patients were transferred to the operating table. In the forced-air warming system group, the upper body blanket was attached with tape at the level of the umbilicus, thus covering the anterior chest, upper extremities, and neck; in addition, the blower was set at a high level (temperature, $43^{\circ} \mathrm{C}$ ). In the circulating-water mattress group, the temperature of the circulating-water mattress was set at maximum (temperature, $41^{\circ} \mathrm{C}$ ).

Shivering was graded using a scale similar to that validated by Tsai and Chu [9]: 0, no shivering; 1 , piloerection or peripheral vasoconstriction but no visible shivering; 2 , muscular activity in only one muscle group; 3 , muscular activity in more than one muscle group but not generalized; and 4 , shivering involving the whole body. A verbal analogue score (VAS) for thermal comfort (0, extremely cold; 5 , thermally neutral; and 10, extremely hot) was recorded prior to anesthesia, at $30 \mathrm{~min}$ intervals intraoperatively, and in the recovery room. The occurrence of shivering during surgery and in the recovery room was recorded. Hypotension (systolic blood pressure $<90 \mathrm{mmHg}$ ) and bradycardia (heart rate $<50$ beats $/ \mathrm{min}$ ) were treated using $4 \mathrm{mg}$ of ephedrine and $0.5 \mathrm{mg}$ atropine bolus, respectively, and treatment were repeated, as needed.

Sample size and power calculations revealed that 23 patients in each group would be required to indicate a $0.5^{\circ} \mathrm{C}$ difference 
in core temperature between both groups with a SD of $0.6^{\circ} \mathrm{C}$ calculated from previous data [10] and a power of $80 \%$ at an alpha level of 0.05 . Both groups were compared using the t-test or Mann-Whitney test, and $\chi^{2}$-test. Continuous data measured over time were analyzed by repeated measures analysis of variance. Data are presented as mean $\pm \mathrm{SD}$, and $\mathrm{P}$ value $<0.05$ were considered statistically significant.

\section{Results}

The demographic data of the patients are provided in Table 1. No significant differences in patient characteristics, anesthesia

Table 1. Demographic Data and Anesthetic Details of Patients Warmed with Either Forced-air or Circulating-water during Total Knee Arthroplasty

\begin{tabular}{lcc}
\hline & $\begin{array}{c}\text { Forced-air } \\
(\mathrm{n}=23)\end{array}$ & $\begin{array}{c}\text { Circulating-water } \\
(\mathrm{n}=23)\end{array}$ \\
\hline Age & $75.8 \pm 4.0$ & $73.1 \pm 3.9$ \\
Sex $(\mathrm{M} / \mathrm{F})$ & $8 / 15$ & $7 / 16$ \\
Height $(\mathrm{cm})$ & $150.2 \pm 8.8$ & $145.1 \pm 6.5$ \\
Weight $(\mathrm{kg})$ & $53.4 \pm 5.1$ & $54.2 \pm 5.0$ \\
Duration of anesthesia $(\mathrm{min})$ & $152.5 \pm 15.2$ & $149.8 \pm 13.1$ \\
Estimated blood loss $(\mathrm{ml})$ & $370.6 \pm 80.0$ & $363.9 \pm 76.6$ \\
Volume of crystalloids $(\mathrm{ml})$ & $1679.3 \pm 450.0$ & $1810.8 \pm 403.2$ \\
Temperature of operation room $\left({ }^{\circ} \mathrm{C}\right)$ & $21.5 \pm 1.5$ & $22.0 \pm 0.7$ \\
Temperature of recovery room $\left({ }^{\circ} \mathrm{C}\right)$ & $24.0 \pm 1.9$ & $24.3 \pm 1.5$ \\
Level of sensory block & & \\
T8 & 1 & 2 \\
T9 & 4 & 3 \\
T10 & 16 & 16 \\
T11 & 2 & 1 \\
T12 & 0 & 1 \\
\hline
\end{tabular}

Values are number or mean \pm SD. No significant differences between groups.

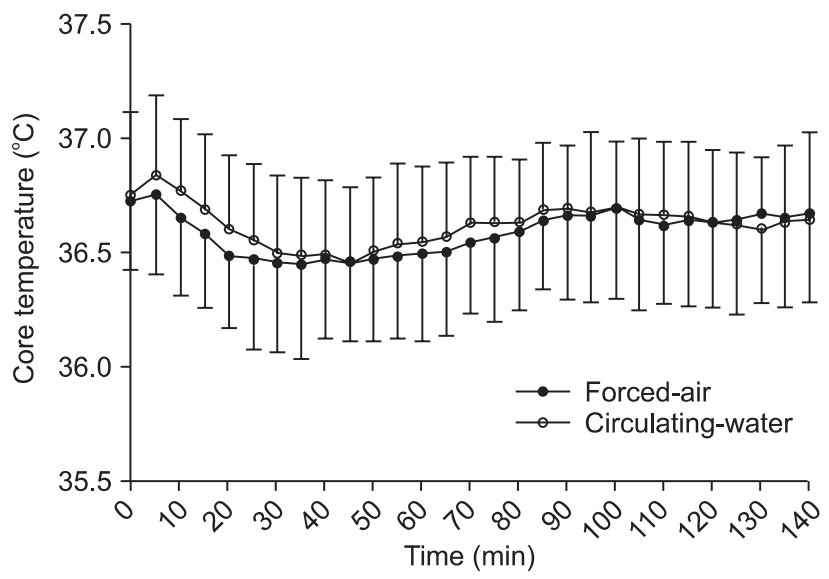

Fig. 1. Changes in core (rectal) temperature over time in patients undergoing total knee arthroplasty and warmed with forced-air $(n=23)$ or circulating-water $(n=23)$ group. First rectal temperature recorded after initial equilibration. duration, or sensory block level were noted between the forcedair and circulating-water groups. Changes in core temperatures over time were not statistically significant between the groups (Fig. 1). However, the final VAS for thermal comfort was significantly lower in the circulating-water group than in the forced-air group $(\mathrm{P}<0.05)$. There were no significant differences between both groups in the VAS for thermal comfort that was measured every $30 \mathrm{~min}$ in the operating room. Post-anesthesia shivering of all patients occurred in the recovery room except for one patient in the circulating-water group. The overall incidence of post-anesthesia shivering was significantly lower in the forced-air group compared to that in the circulating-water group $(\mathrm{P}<0.05)$. The severity of post-anesthesia shivering was also significantly less in the forced-air group $(\mathrm{P}<0.05)$ (Table 2$)$. Hypotension was observed in 6 patients in two groups, and bradycardia occurred in 2 patients in the circulating-water group, and ephedrine and atropine were administered for these cases, respectively. There were no significant differences in the incidences of hypotension and bradycardia.

\section{Discussion}

We compared the efficacy of a forced-air warming system and a circulating-water mattress in elderly patients vulnerable to hypothermia to prevent hypothermia and post-anesthesia shivering under spinal anesthesia. The circulating-water mattress resulted in body temperature changes that were similar to those achieved with the forced-air warming system. However, the forced-air warming system was more effective than the circulating-water mattress in reducing the incidence of post-anesthesia shivering.

Post-anesthesia shivering is a common complication that may occur in patients who have undergone surgery. The reported incidence of postoperative shivering is $5-65 \%$, whereas $11.6 \%$ of patients experience moderate post-anesthesia shivering. Shivering occurs more frequently after spinal anesthesia is induced, with an incidence of $56.7 \%$ [11]. In the present study, the overall

Table 2. Verbal Analogue Scale (VAS) for Thermal Comfort, Incidence and Intensity of Post-anesthesia Shivering in Patients Undergoing Total Knee Arthroplasty and Warmed by Forced-air or Circulating-water Group

\begin{tabular}{lcc}
\hline & $\begin{array}{c}\text { Forced-air } \\
(\mathrm{n}=23)\end{array}$ & $\begin{array}{c}\text { Circulating-water } \\
(\mathrm{n}=23)\end{array}$ \\
\hline First VAS for thermal comfort & $4.8 \pm 0.5$ & $4.4 \pm 0.5$ \\
Final VAS for thermal comfort & $5.0 \pm 0.5^{*}$ & $4.0 \pm 0.7$ \\
$\begin{array}{l}\text { Incidence of post-anesthesia shivering } \\
\text { Intensity of post-anesthesia shivering } \\
(0 / 1 / 2 / 3 / 4)\end{array}$ & $\begin{array}{c}3(13.0)^{*} \\
20 / 2 / 1 / 0 / 0^{*}\end{array}$ & $10(43.5)$ \\
& & \\
\hline
\end{tabular}

Values are number or mean \pm SD or number of patients $(\%) . * \mathrm{P}<0.05$ compared to Circulating-Water group. 
incidence of post-anesthesia shivering was consistent with previous reported results. A high level of muscle activity may interfere with the results of blood pressure monitoring, electrocardiography, and pulse oximetry and may also negatively affect patient comfort [12]. Shivering may increase oxygen consumption by $400-500 \%$ and induce tachycardia and hypertension. It may also be associated with increased intracranial and intraocular pressure and increased carbon dioxide production [13]. The increase in metabolic demand increases the difficulties in patients with fixed lung capacity and limited cardiac output [14,15]. In particular, in the case of elderly patients in the present study, mixed venous oxygen saturation is reduced and arterial blood becomes hypoxic, leading to respiratory and metabolic acidosis

There has been much debate about whether post-anesthesia shivering occurs only in cases of hypothermia due to heat loss. According to Jones and McLaren [16], decreasing body temperature measured through the esophagus is correlated with the frequency of post-anesthesia shivering. However, in the present study there were no statistical differences in core temperature between patients who experienced post-anesthesia shivering and those who did not. Although post-anesthesia shivering develops as a normal physiological response to hypothermia in most cases, it can also occur as a consequence of many other factors, including uninhibited spinal reflexes, decreased sympathetic activity, pyrogen release, adrenal suppression, and respiratory alkalosis [17]. It can also occur as a non-thermoregulatory response to inadequate pain control. Mild perioperative hypothermia does not necessarily develop prior to the occurrence of postanesthesia shivering; however, the occurrence of perioperative hypothermia exacerbates post-anesthesia shivering. Moreover, the probability of developing post-anesthesia shivering increases with an increase in the severity of hypothermia [18]. As mentioned above, the cause of post-anesthesia shivering is not clear. However, various methods have been used for prevention and treatment of post-anesthesia shivering including heating of the operating room, skin surface warming, and drugs such as meperidine, clonidine, morphine, fentanyl, nalbuphine, tramadol, and ondansetron $[19,20]$.

Core temperature is defined as the temperature of the blood perfusing the hypothalamus, and it is usually measured via the esophagus, nasopharynx, or tympanic membrane. Unless body temperature rapidly changes in extracorporeal circulation, a relatively accurate temperature can be measured via the bladder or rectum. Introduction of a rectal thermistor in close proximity to the surgical site is likely to result in a sanitary problem. Moreover, discomfort of a conscious patient as well as errors that may develop due to the presence of feces may occur. In the present study, the thermometer was inserted after spinal anesthesia was applied in order to minimize patient discomfort.

During surgery, most patients experience a decrease in body temperature that may be caused by multiple complex factors, including thermoregulatory disability resulting from anesthesia and a low temperature in the operating room. Patients with a large body surface area, elderly patients or children are at risk of hypothermia. Additional risk factors of hypothermia include a wide incision, exposure of the wound, and neuropathy [21]. Temperature monitoring and maintenance are essential to prevent hypothermia. The effect of spinal anesthesia on homeostasis of body temperature has been studied extensively. For example, in a study of patients receiving spinal anesthesia, a high level of spinal blockade and advanced age were predictors of hypothermia. It is interesting to note that the duration of surgery, ambient operating room temperature, and body habitus were not predictors of hypothermia [4].

The influences of other factors were excluded as much as possible to compare the effects of both types of warming devices on body temperature and post-anesthesia shivering. Intravenous infusion of large amounts of cold fluids can cause severe loss of heat. Administration of $1 \mathrm{~L}$ of refrigerated fluid and 1 unit of refrigerated blood decreases core body temperature by approximately $0.25^{\circ} \mathrm{C}[22]$. To address this, all fluids were administered via a warmer. In both groups, anesthesia was administered at the lowest possible spinal level, since a higher level of blockade is associated with greater severity of hypothermia. A previous study has shown that the administration of ephedrine minimized the decrease in the core temperature [23]. However, patients in the present study treated with these drugs exhibited no apparent changes in the body temperature after administration, possibly due to the relatively low doses of the drugs used.

Minimizing the differences between core and skin temperatures is useful in the prevention of redistribution hypothermia. The forced-air warming system is widely used since it is both inexpensive and safe. However, although inexpensive, cost remains a concern because the air blanket cannot be reused. Moreover, the hose and the warming unit are potential sites for bacterial colonization, probably due to the difficulty in cleaning these parts [24]. The circulating-water mattress has no hose or hidden spaces, and is easier to clean and disinfect than the forced-air warming system. According to the results of this study, the ability to maintain the core temperature was not significantly different between both devices. However, as mentioned earlier, there was a difference in the incidence of post-anesthesia shivering. The forced-air warming system is known to be more useful in maintaining normothermia compared to the circulating-water mattress and to the humidifier with a heated-wire breathing circuit [25]. In addition, having greater body surface area through which heat can be delivered is also known to increase efficacy. We believe that the core temperature was not a crucial factor in determining the occurrence of post-anesthesia shivering, but that increasing skin temperature could reduce the frequency and 
severity of post-anesthesia shivering [26]. Subsequent studies to measure skin temperature will help to support this hypothesis.

There are certain limitations to our study. When the temperature of the operating room is reduced to below $21^{\circ} \mathrm{C}$, the frequency of hypothermia rapidly increases [27]. However, the temperature of the operating room was maintained slightly lower at $20-22^{\circ} \mathrm{C}$ by request of the surgeon for hypothermic manipulation of the bone cement. Moreover, we did not compare the groups undergoing both warming strategies with a control group; we considered it unethical to expose a control group to the risks associated with perioperative hypothermia. Finally, there was a difference in the time at which both warming de- vices were applied. The forced-air warming blanket was applied only after the induction of anesthesia, whereas the circulatingwater mattress was switched on before the patient was transferred to the operating table.

In conclusion, the forced-air warming system was more effective than the circulating-water mattress in reducing the incidence and severity of post-anesthesia shivering in elderly patients undergoing total knee arthroplasty.

\section{Acknowledgments}

This paper was supported by Konkuk University in 2013.

\section{References}

1. Sessler DI. Perioperative heat balance. Anesthesiology 2000; 92: 578-96.

2. Reynold L, Beckmann J, Kurz A. Perioperative complications of hypothermia. Best Pract Res Clin Anaesthesiol 2008; $22: 645-57$.

3. Butterworth JF, Wasnick JD. Morgan \& Mikhail's Clinical Anesthesilogy. 5th ed. New York, McGraw-Hill. 2013, pp 1184-5.

4. Frank SM, El-Rahmany HK, Cattaneo CG, Barnes RA. Predictors of hypothermia during spinal anesthesia. Anesthesiology 2000; 92: 13304.

5. Ozaki M, Sessler DI, Matsukawa T, Ozaki K, Atarashi K, Negishi C, et al. The threshold for thermoregulatory vasoconstriction during nitrous oxide/sevoflurane anesthesia is reduced in the elderly. Anesth Analg 1997; 84: 1029-33.

6. Sessler DI. Mild perioperative hypothermia. N Engl J Med 1997; 336: 1730-7.

7. Ng V, Lai A, Ho V. Comparison of forced-air warming and electric heating pad for maintenance of body temperature during total knee replacement. Anaesthesia 2006; 61: 1100-4.

8. Fanelli A, Danelli G, Ghisi D, Ortu A, Moschini E, Fanelli G. The efficacy of a resistive heating under-patient blanket versus a forced-air warming system: randomized controlled trial. Anesth Analg 2009; 108: 199-201.

9. Tsai YC, Chu KS. A comparison of tramadol, amitriptyline, and meperidine for postepidural anesthetic shivering in parturients. Anesth Analg 2001; 93: 1288-92.

10. Brandt S, Oguz R, Hüttner H, Waglechner G, Chiari A, Greif R, et al. Resistive-polymer versus forced-air warming: comparable efficacy in orthopedic patients. Anesth Analg 2010; 110: 834-8.

11. Chen JC, Hsu SW, Hu LH, Hong YJ, Tsai PS, Lin TC, et al. Intrathecal meperidine attenuates shivering induced by spinal anesthesia. Ma Zui Xue Za Zhi 1993; 31: 19-24.

12. Barker SJ, Shah NK. Effects of motion on the performance of pulse oximeters in volunteers. Anesthesiology 1996; 85: 774-81.

13. Rosa G1, Pinto G, Orsi P, de Blasi RA, Conti G, Sanitá R, et al. Control of post anaesthetic shivering with nefopam hydrochloride in mildly hypothermic patients after neurosurgery. Acta Anaesthesiol Scand 1995; 39: 90-5.

14. Ciofolo MJ, Clergue F, Devilliers C, Ben Ammar M, Viars P. Changes in ventilation, oxygen uptake, and carbon dioxide output during recovery from isoflurane anesthesia. Anesthesiology 1989; 70: 737-41.

15. Just B, Delva E, Camus Y, Lienhart A. Oxygen uptake during recovery following naloxone. Relationship with intraoperative heat loss. Anesthesiology 1992; 76: 60-4.

16. Jones HD, McLaren CA. Posoperative shvering and hypoxaemia after halothane, nitrous oxide and oxygen anaesthesia. Br J Anaesth 1965; 37: $35-41$

17. Horn EP. Postoperative shivering: aetiology and treatment. Curr Opin Anaesthesiol 1999; 12: 449-53.

18. Lienhart A, Fiez N, Deriaz H. Postoperative shivering: analysis of main associated factors. Ann Fr Anesth Reanim 1992; 11: 488-95.

19. Alfonsi P, Hongnat JM, Lebrault C, Chauvin M. The effects of pethidine, fentanyl and lignocaine on postanaesthetic shivering. Anaesthesia 1995; 50: 214-7.

20. Wang JJ, Ho ST, Lee SC, Liu YC. A comparison among nalbuphine, meperidine, and placebo for treating postanesthetic shivering. Anesth Analg 1999; 88: 686-9.

21. Kasai T, Hirose M, Yaegashi K, Matsukawa T, Takamata A, Tanaka Y. Preoperative risk factors of intraoperative hypothermia in major surgery under general anesthesia. Anesth Analg 2002; 95: 1381-3.

22. Sessler DI. Temperature regulation and monitoring. In: Miller's Anesthesia. 7th ed. Edited by Miller RD: New York, Churchill-Livingstone Elsevier. 2010, pp 1533-56. 
23. Vallerand AL. Effects of ephedrine/xanthines on thermogenesis and cold tolerance. Int J Obes Relat Metab Disord 1993; 17 Suppl 1: S53-6.

24. Baker N, King D, Smith EG. Infection control hazards of intraoperative forced air warming. J Hosp Infect 2002; 51: 153-4.

25. Hynson JM, Sessler DI. Intraoperative warming therapies: a comparison of three devices. J Clin Anesth 1992; 4: 194-9.

26. Lopez M, Sessler DI, Walter K, Emerick T, Ozaki M. Rate and gender dependence of the sweating, vasoconstriction, and shivering thresholds in humans. Anesthesiology 1994; 80: 780-8.

27. Morris RH. Operating room temperature and the anesthetized, paralyzed patient. Arch Surg 1971; 102: 95-7. 